\title{
Research on the (establishment of) path of realizing the targeted poverty alleviation through tourism under the perspective of all-for- one tourism
}

\author{
SU Dan \\ Ordos Institute Of Technology, Inner Mongolia,017000
}

\begin{abstract}
Under the strategic perspective of building a moderately prosperous society in an all-round way, General Secretary Xi Jinping put forward the guiding ideology of "precise poverty alleviation". The report of the 19th National Congress of the Communist Party of China also pointed out that the main contradictions in my country's society have been transformed, and tourism is the top of the happy and green industries. Industry is an important symbol of the improvement of people's living standards. Taking tourism development as an entry point has become another effective measure for targeted poverty alleviation. The concept of all-for-one tourism has pointed out the direction for the development of the tourism industry, which is conducive to the improvement of regional economic levels and is an effective means of tourism poverty alleviation. Based on the discussion of allfor-one tourism and targeted poverty alleviation, this article analyzes the current development of tourism in Ejin Horo Banner of the Ordos and the status quo of tourism poverty alleviation, explore the path to achieve tourism poverty alleviation to help Inner Mongolia achieve comprehensive poverty alleviation by the study of the coupling mechanism of the two.

Tourism poverty alleviation is the most typical type of industrial poverty alleviation, and it is a powerful starting point and focus for building a moderately prosperous society in an all-round way. In this process, as a new research horizon, all-for-one tourism has realized the completeness of tourism in terms of space, industry, elements and management. It is an important means of tourism poverty alleviation, and the coupling mechanism of all-for-one tourism and tourism poverty alleviation should provide a new paradigm for further expanding the realization path of targeted poverty alleviation
\end{abstract}

\section{Discussion of related concepts}

All-for-one tourism refers to the active integration of various industries, the joint management of all departments, the participation of the residents of the city, the full use of all the attractions of the destination, and the full-process, full-time experience products for tourists who come to travel, so as to fully satisfy all-round experience needs of tourists ( $\mathrm{Li}$ Xinjian, 2013).In August 2015, the national tourism administrative department first proposed the development strategy of global tourism, which clarified the basic concepts of global tourism in terms of the regional restrictions of global tourism, the true positioning of the tourism industry, the participants and the realization of goals, etc. (Li Jinzao, 2016). All-for-one tourism drives the overall economic development with all-round development of tourism, and promotes the optimization and upgrading of regional industries at the same time, with the development of beautiful rural areas as a new starting point, becoming a new focus of the next step of the economy development. All-forone tourism is the main line of the 13th Five-Year Plan for tourism industry, a new idea to guide future tourism, and an inevitable choice to solve the current economic transformation dilemma.

\section{Coupling effect with tourism targeted poverty alleviation from the perspective of all-for-one tourism}

The characteristics of all-for-one tourism are comprehensive, including all attractions, all industries, all-time, all people. Using tourism as the mainstay of economic development, through overall planning, it breaks through regional restrictions and limitations, forms new economic development channels and patterns, and becomes the new power point and platform of tourism poverty alleviation. As we all know, most of the tourist poor areas are concentrated

topsudan@163.com 
in relatively remote areas with inconvenient transportation. Traditional tourism also stays based on pristine natural scenery. The poverty alleviation paradigm is mostly "Angertainment". These tourism projects are single, and the expansion of tourism products is low, and cannot form a long-term attraction, lack of market competitiveness. The all-for-one tourism proposed in the "13th Five-Year Plan" is based on solving the above shortcomings and difficulties in the development of rural tourism. By breaking the bottleneck of rural tourism, concentrating superior resources, creating characteristic tourism projects, unifying the layout of rural tourism planning, it promotes rural tourism and increases the capabilities of poverty alleviation service. At the same time, the coupling of all-for-one tourism and tourism poverty alleviation enables all-for-one tourism to exert agglomeration and scale effects, upgrade the overall industry of the tourism economy, and form lasting vitality. With the development of all-for-one tourism, it can promote the employment of people in poverty areas, increase income growth, and empower locals with the means to prosper, fundamentally reverse the appearance of poor rural areas, and truly realize rural revitalization. All-for-one tourism and tourism targeted poverty alleviation are the fusion of points and areas. They are the deep integration of various industries such as tourism, agriculture, culture, and the Internet and are all dimensional cooperation. In the entire economic chain, special attention should be paid to the protection of the ecological environment, adhere to green governance and adhere to the country's strategic deployment of sustainable development.

In the process of tourism poverty alleviation, As the development of tourism resources exerts pressure on the ecological environment, it is necessary to carry out ecological protection and increase investment to improve the efficiency of ecological environment protection and create a good ecological environment, and to improve the level of tourism poverty alleviation. To make the two systems of tourism poverty alleviation and ecological environment mutually promote each other, forming a coupling pattern of virtuous circular development. Please look at Fig.1.

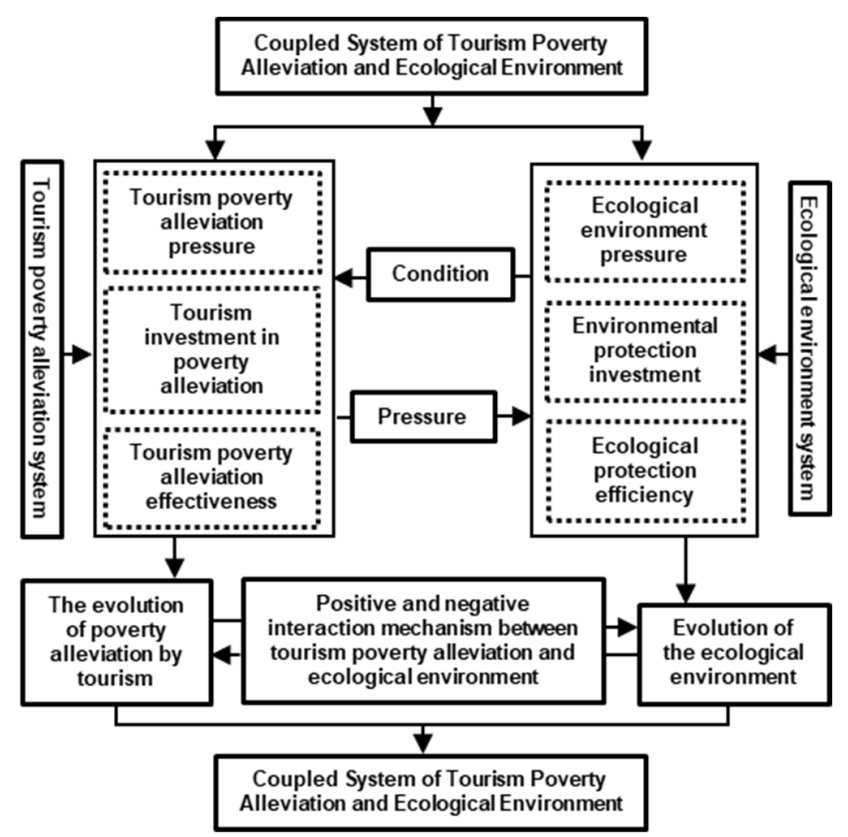

Fig 1. The coupling coordinated drive mechanism assessment model framework of the poor tourism and ecoenvironment.

\section{The reconstruction path of alleviating tourism poverty from the perspective of global tourism}

\subsection{Do top-level design well and strengthen overall planning of global tourism integration}

The development of global tourism involves many aspects, such as the construction of tourism infrastructure, the construction of tourism environment, the cultivation of tourism form, the development of tourism resources and the construction of tourism products. It is a new concept and mode of coordinated development. It is an industry that requiress large investment and fine operation. The conditions and foundation for comprehensive development can only be achieved by continuous thinking, industry and talent accumulation, which cannot be achieved overnight.

In order to ensure the smooth progress of global tourism, the priority is to play and mobilize the role of the municipal global tourism leadership team, in order to effectively solve and coordinate the difficulties and problems in the work. The second is to establish scientific rationality and 'a board of chess' thinking mode to develop global tourism, accelerate the improvement of the existing tourism overall planning, do a good job of tourism and forestry, agriculture and animal husbandry, transportation and other related industrial planning convergence, especially to promote the convergence of key tourist attractions planning and rural revitalization planning, and promote more people to participate in the development and construction of global tourism. According to the development level of tourism 
industry in each banner or county, guidance documents such as scenic spots upgrading, tourism transportation facilities improvement, tourism route planning and design, and overall development of products should be formulated according to local conditions and classification. The red line of tourism development and development in each region should be delimited, and the bottom line of the environment should be firmly adhered to. Resources should be integrated, implementation should be taken step by step, and promoted emphatically, so as to avoid coaxing, repeated construction and homogeneous competition.

Strengthening the compilation and implementation of global tourism planning and special planning Different from the traditional tourism planning, the four characteristics of global tourism are panoramic, all-time, all-industry and allpeople. We should adhere to the guiding principle of planning, in accordance with the requirements of Outline of the Thirteenth Five-Year Plan for National Economic and Social Development of Ordos City. In the process of building a national global tourism demonstration area, we should give full consideration to the integration of multiple planning, intensive strength, and highlight the leading role of tourism in the global industry. It is suggested that the Municipal Tourism Administration and relevant departments should further strengthen the compilation and implementation of Overall Tourism Planning of Ordos City in accordance with the principles of comprehensive grasp, comprehensive management and comprehensive construction, and work closely around the development principles, development strategies, image positioning, development goals, ways of realization, spatial structure, functional zoning and product system construction.

\subsection{To coordinate the public service elements of tourism development and make up for the shortcomings of tourism development}

1. Strengthening public service mechanism and assigning all elements to tourism poverty alleviation.

The development of tourism elements in Ordos is slow and loose. The six elements of 'eating, accommodation, transportation, travel, purchase and entertainment ' are different in degrees, and the different links in the chain are not open. The industrial chain is short, and the infrastructure is imperfect, resulting in the 'short board effect' of industrial development. It is difficult to have a look, enjoy the trip, live comfortably, eat satisfactorily, buy well, talk deeply, worship greatly, cure perfectly, travel deeply, study fundamentally, enjoy contently, and return with satisfaction. In view of the above problems, we should start from the six elements of tourism and strengthen the matching of all elements.

2. Improving traffic facilities and promoting tourism spatial integration

The tourist traffic facilities in Ordos City are not perfect, and the public transport in the city stops operating after seven o 'clock in the evening, which will lead to inconvenience for tourists to travel at night and cannot completely release the vitality of the tourism industry. Therefore, it is necessary to improve the travel and traffic system as the basic focus to promote the integration of tourism space, accelerate the construction or expansion of key tourist routes and traffic marking systems between scenic spots and adjacent areas within the city, comprehensively improve the accessibility and accessibility of tourism, and ensure the smooth connection of tourism export channels. It is suggested that the new structure of global spatial network should be constructed by combing and connecting roads, towns, villages, scenic spots and resorts, so that the ecological value and humanistic value of tourism resources can be released in global tourism. In terms of public transport services, it is necessary to optimize and upgrade the transport network, upgrade the public transport line and tourism line, do a good job of connecting traffic in urban areas and scenic areas, shorten the waiting time of public transport, and encrypt the vehicle capacity, so as to provide the maximum range of convenience for tourists to and from urban areas, scenic areas, hotels, airports and stations. At the same time, the popularization of sharing economy and tourists' self-driving tour should also be recommended to provide convenience for creating efficient and humanized travel.

\subsection{Improving the tourism product system and enhancing tourism characteristics and brand products}

1. Building a diversified tourism product system and diversified new forms of tourism development

There are more than 30 large-scale tourist attractions in Ordos (5A / 4A,) such as Genghis Khan Mausoleum, forming a tourism product hierarchy with $5 \mathrm{~A}$ as the leader, $4 \mathrm{~A}$ as the main body, and other scenic spots as the supplement. Existing tourism products have developed natural sightseeing, leisure vacation, cultural experience and other types of tourism products around Ordos desert, grassland, water, religion and other resources, and the product system has been gradually improved. However, in the process of product development, the quality of resources has not been released to the maximum, and there is a lack of truly visible and selling products. Tourism product development is still in the primary stage. The supply of products is still in the stage of sightseeing economy, scenic economy and ticket economy, and does not form a sound product system to meet the needs of modern tourism. In the near future, it is in great need of furthering optimization and creating super first-class products with first-class resources. It is suggested to increase the in-depth excavation of grassland tourism culture, highlight the tourism products with Mongolian characteristics and customs, such as Mongolian song and dance, Mongolian horse culture, Mongolian catering and other characteristic elements, and form tourism characteristic brands such as grassland scenery sightseeing, rural leisure vacation, ice and snow stimulation 
adventure, historical and cultural experience. Genghis Khan Mausoleum, as a sacred place for the Eight White House of Genghis Khan, has unique folk songs and dances, court etiquette, customs and folk culture, but the display of these cultural elements lacks a centralized and popular platform.

2.Strengthening development of rural tourism, winter tourism and experiential tourism products

Ordos tourism products are highly similar, facing fierce competition in product homogeneity market, serious internal consumption, uneven quality of tourism products, fewer brand tourism products, a lack of broad and lasting market influence, which is not conducive to the healthy development of the whole Ordos tourism industry. It is suggested to strengthen the development of characteristic and brand tourism products and establish a rich product system integrating sightseeing, leisure and vacation. First, in terms of rural tourism, the overall development of rural tourism should be carried out by relying on the beautiful natural pastoral scenery and complete rural tourism facilities in Ordos, in accordance with the principle of 'one village, one brand, one household, one feature' and various financing channels such as PPP, and according to the village-based rural tourism cluster and courtyard leisure. New development models, such as holidays, garden-style characteristic agricultural industry, ancient street folk tourism, have created a number of pastoral tourism complexes.

At the same time, five modes --'project driven ', 'scenic spot driven ', ' travel agency driven ', 'hotel driven' and 'enterprise driven' are used to promote the direct or indirect employment of farmers and herdsmen, realizing the transformation of agricultural and sideline products into local sales of tourism commodities, so that more people can eat 'tourism meal'. It not only improves the tourism characteristics, but also realizes the goal of making local people rich through tourism. Second, in terms of winter tourism, we should focus on developing a group of tourism projects with attractions and selling points. Relying on the source-stream scenic spots of Mongolia, we should combine winter tourism with historical and traditional elements such as Mongolian winter holy fire worship and Mongolian New Year celebration, and national characteristics and culture. More attention should be paid to enhance tourists' experience, seize the excitement and interest of tourists. Design and launch a group of participatory and experiential products in a specific period of time so that tourists can feel the most primitive and authentic Mongolian customs in the cold winter. Third, in terms of experiential tourism, we should rely on the hardware facilities of rural tourism to develop it into a short-term apartment for leisure and vacation, and use platforms such as 'mayi.com (a short rent)'and 'MeiTuan' to open to tourists, which can not only provide convenient and comfortable modern family services for tourists, but also increase the tourism income of farmers and herdsmen. At the same time, living in short-term apartments for leisure and vacation tourists can experience the production of yogurt, milk tea and other characteristic products in the homes of farmers and herdsmen, and fully experience the daily life and national customs of Mongolian people.

\section{References}

1. Donaldson,J,2016,How China Escaped the Poverty Trap,Ithaca and London:Cornell University Rress.

2. M. Young, The Technical Writer's Handbook. Mill Valley, CA: University Science, 1989.

3. Wang G.H.On the path and methods of the strategic implementation of all-for-one tourism[J].Journal of Beijing Union University ,2017,15(3), 12-18.

4. Cai Y .X,Liu T.Design and implementation of the freight information service system based on LBS[J].Geospation Security,2013(12).6161-6165. 